\title{
A Differentially Driven Dual-Polarized Dual-Wideband Complementary Antenna for 2G/3G/LTE Applications
}

\author{
Botao Feng, ${ }^{1}$ Shufang Li, ${ }^{1}$ Wenxing An, ${ }^{2}$ Weijun Hong, ${ }^{1}$ and Sixing Yin ${ }^{1}$ \\ ${ }^{1}$ Beijing Key Laboratory of Network System Architecture and Convergence, Beijing University of Posts and Telecommunications, \\ Beijing 100876, China \\ ${ }^{2}$ Department of Electronic Engineering, School of Information Science and Technology, Tsinghua University, Beijing 100084, China
}

Correspondence should be addressed to Botao Feng; fengbotao@bupt.edu.cn

Received 23 March 2014; Revised 3 May 2014; Accepted 7 May 2014; Published 2 June 2014

Academic Editor: Miguel Ferrando Bataller

Copyright (C) 2014 Botao Feng et al. This is an open access article distributed under the Creative Commons Attribution License, which permits unrestricted use, distribution, and reproduction in any medium, provided the original work is properly cited.

\begin{abstract}
A novel differentially driven dual-polarized dual-wideband complementary patch antenna with high isolation is proposed for 2G/3G/LTE applications. In order to generate dual-polarization and dual-wideband properties, a pair of biorthogonal dual-layer $\eta$-shaped tapered line feeding structures is utilized to feed two pairs of dual-layer U-shaped patches, respectively. The upper-layer U-shaped patches mainly serve the upper frequency band, while the lower-layer ones chiefly work for the lower frequency band. Besides, a horned reflector is introduced to improve radiation patterns and provide stable gain. The prototype antenna can achieve a bandwidth of $25.7 \%(0.78 \mathrm{GHz}-1.01 \mathrm{GHz})$ with a stable gain of $7.8 \pm 0.7 \mathrm{dBi}$ for the lower band, and a bandwidth of $45.7 \%$ $(1.69 \mathrm{GHz}-2.69 \mathrm{GHz})$ with a gain of $9.5 \pm 1.1 \mathrm{dBi}$ for the upper band. Input isolation exceeding $30 \mathrm{~dB}$ has been obtained in the wide bandwidth. Thus, it can be potentially used as a base station antenna for $2 \mathrm{G} / 3 \mathrm{G} / \mathrm{LTE}$ networks.
\end{abstract}

\section{Introduction}

In recent years, dual-polarized antenna has become one of the favourite choices of antenna designers due to its attractive features, such as doubled capacity of communication systems by frequency reuse, reduced multipath fading of received signals by polarization diversity, and improved transmit-receive isolation. In order to improve isolation and broaden impedance bandwidth, many designs of dual-polarized antennas have been reported [1-7]. With the help of dielectric-loaded monopole [1], port isolation better than $20 \mathrm{~dB}$ and a bandwidth greater than $12 \%$ have been acquired. Then, by using L-shaped probe cooperating with cross slots [2-4], input isolation exceeding $25 \mathrm{~dB}$ and impedance bandwidth of over $20 \%$ have been obtained. After that, by means of the proximity coupling or multilayer dielectric plate collaborated with orthogonal slots $[5,6]$, isolation more than $34 \mathrm{~dB}$ and a bandwidth of over $22 \%$ have been achieved. Recently, with differentially driven inverted U-shaped feeding structure [7], port isolation better than $36 \mathrm{~dB}$ and a bandwidth greater than $62 \%$ have been attained.
On the other hand, in the past few years, Prof. Luk and his team have developed a novel kind of magnetoelectric (ME) dipole antenna [3,7-10], which can meet the high requirements of wideband mobile communications due to its excellent electrical characteristics, such as low crosspolarization, low back-lobe radiation, stable gain across the operating band, and nearly identical $E$ - and $H$-plane patterns. In order to further satisfy the needs of $2 \mathrm{G} / 3 \mathrm{G} / \mathrm{LTE}$ communication networks, recently, dual-wideband ME dipole antennas, which have the advantages such as reduced numbers of antennas and minimized installation area, have been presented in $[11,12]$.

However, there are few researches on differentially driven dual-polarized ME dipole antenna [7]. The antenna proposed in [7] cannot cover the 2G/3G/LTE frequency band. In addition, it is not a dual-wideband antenna. Hence, a differentially driven dual-polarized dual-wideband ME dipole antenna, which possesses all the advantages as mentioned above, is highly desirable.

In this paper, a differentially driven dual-polarized dualwideband ME dipole antenna (complementary antenna) with 
a biorthogonal feeding structure is proposed. To the best of our knowledge, the proposed antenna is the first differentially driven dual-polarized dual-wideband ME dipole antenna. With the novel dual-layer structure (including dual-layer electric dipoles, biorthogonal dual-layer $\eta$ feeding structure, and horned reflector), good performance in terms of dualwideband impedance bandwidth, stable and high gain, stable unidirectional radiation, and high front-to-back ratio can be realized. Besides, owing to nearly symmetrical dualpolarization structure and excitation, good performance in cross-polarization radiation and high isolation can be attained. Moreover, compared with the conventional singleport excited ME dipole antenna [8,10-13], the proposed antenna can be conveniently used in differential microwave circuits. Finally, the proposed antenna, which is completely made of copper patches without dielectric loading, can be easily fabricated at relatively low cost and thus it is practicable for 2G/3G/LTE applications. In order to analyse the antenna structure effectively, we simply study its $S$ parameters formula and operating principle to guide the design. Measurements and simulations are then performed to verify the design.

\section{Antenna Description and Design Geometry}

Basically, the proposed antenna consists of two pairs of double-layer U-shaped electric dipoles with apertures, two pairs of shorted walls, a pair of biorthogonal dual-layer $\eta$-shaped feeding structures and a horned reflector. The dimensions of the antenna are $206 \times 166 \times 88 \mathrm{~mm}^{3}$. Besides, the thickness of the copper patches is selected for $0.3 \mathrm{~mm}$ after taking the versatility and cost into consideration.

\subsection{Dual-Layer U-Shaped Magnetoelectric Dipole Geometry.} The geometry of the proposed antenna is shown in Figure 1. From the top view, it is easily seen that an upper-layer Ushaped patch comprises an isosceles trapezoid $\left(L_{4} \times L_{6} \times L_{8}\right)$ and a pair of rectangles $\left(L_{3} \times W_{3}\right)$, while a lower-layer $\mathrm{U}$ shaped patch consists of an isosceles trapezoid $\left(L_{2} \times L_{6} \times L_{7}\right)$ and three rectangles (two smaller rectangles' dimensions are $L_{1} \times W_{1}$, while the larger one's dimensions are $L_{2} \times W_{2}$ ). There is a rectangular aperture $\left(L_{5} \times W_{4}\right)$ in each isosceles trapezoid, which can change the current distribution and is equivalent to a radiation element. The $\mathrm{U}$-shaped notches are designed to broaden impedance bandwidth since they can increase the effective electrical length. As shown in the $3 \mathrm{D}$ view and side view, the upper-layer and the lower-layer U-shaped patches are joined by upper vertical folded rectangular patches $\left(\mathrm{H}_{2} \times\right.$ $\left.\left(2 \times L_{8}+L_{6}\right)\right)$. The lower-layer $\mathrm{U}$-shaped patches mainly serve the lower frequency band, while the upper-layer ones chiefly work for the upper frequency band. All of them consist of the double-layer electric dipoles. The lower-layer U-shaped patches are also connected to ground plane through a pair of vertical folded rectangular patches $\left(H_{1} \times\left(2 \times L_{7}+L_{6}\right)\right)$, which are separated by a gap of $24 \mathrm{~mm}\left(G_{2}\right)$. The upper- and lowerlayer vertical folded rectangular patches constitute shorted walls. A pair of parallel vertical shorted walls and the portion of the ground plane between them form a magneto dipole, which is equivalent to a parallel resonant capacitor. A pair of parallel electric dipoles and the magneto dipole jointly make up a ME dipole which is set in the center of a horn-shaped reflector. As shown in the $3 \mathrm{D}$ view, a pair of b-orthogonal ME dipoles form a basic dual-polarized antenna. Excellent complementary electrical characteristics and dual-polarized features can be achieved via mutual coordination between them.

\subsection{Biorthogonal Dual-Layer $\eta$-Shaped Tapered Line Feeding} Structure. In order to excite the antenna to achieve good impedance matching and high isolation simultaneously, a novel biorthogonal dual-layer $\eta$-shaped tapered line feeding structure is introduced. As shown in Figures 1(c) and 1(d), the upper-layer $\eta$-shaped feeding structure is designed to feed the upper-layer U-shaped electric dipole patches, while the lower-layer $\eta$-shaped feeding structure is utilized to feed the lower-layer U-shaped electric dipole patches. In addition, dual-layer $\eta$-shaped tapered-line feeding structure can easily attain good impedance matching, since tapered line can simply provide more degree of freedom for impedance matching in comparison with [14]. In fact, each $\eta$-shaped feeding structure includes a transmission line and a coupling strip. Each tapered line transmission line separates 1-mm $\left(G_{1}\right)$ from one of the nearest vertical shorted wall patches. To feed the antenna with differential signals, they are vertically placed to the ground plane and the bottom ends are connected to SMA connectors underneath the ground plane, respectively. As shown in Figure 1(d), the end of the upper double $\eta$-shaped feeding structure is connected to port 1 , while the lower one is connected to port 2. Each lower-layer coupling strip consists of a horizontal rectangular patch $\left(W_{7} \times W_{12}\right)$ and a vertical isosceles-trapezoid patch $\left(W_{9} \times W_{5} \times H_{4}\right.$ or $\left.W_{10} \times W_{5} \times H_{8}\right)$, the bottom of which is wider than the top. Similarly, each upper-layer coupling strip consists of a horizontal rectangular patch $\left(W_{11} \times W_{5}\right)$ and a vertical rectangular patch $\left(W_{5} \times\right.$ $H_{9}$ ). The horizontal portions couple electrical energy to the antenna, while the vertical portions work together with one of the nearest vertical shorted wall patches to compensate the inductance caused by the horizontal portions, respectively. The length of horizontal portion of coupling strips $\left(W_{11}\right)$ and the distances $\left(H_{11}, H_{12}\right)$ between them not only can affect the impedance matching but also have an obvious influence on antenna port isolation.

2.3. Horn-Shaped Reflector. Figures 1(a) and 1(c) show the geometry of the proposed horned reflector. Both the upper surface and lower surface are squares, whose dimensions are $206 \times 206 \mathrm{~mm}^{2}\left(G_{H} \times G_{H}\right)$ and $166 \times 166 \mathrm{~mm}^{2}\left(G_{L} \times\right.$ $\left.G_{L}\right)$, respectively. The distance between them is $64 \mathrm{~mm}$ $\left(H_{G}\right)$. Instead of a conventional planar ground plane, the horned reflector is specially designed to improve the gain and radiation patterns.

The detailed dimensions for the antenna are summarized in Table 1.

\section{Theory and Parametric Study}

3.1. Theory of Differential-Driven Dual-Polarized ME Dipole Antenna. According to [7] and our nearly symmetrical 


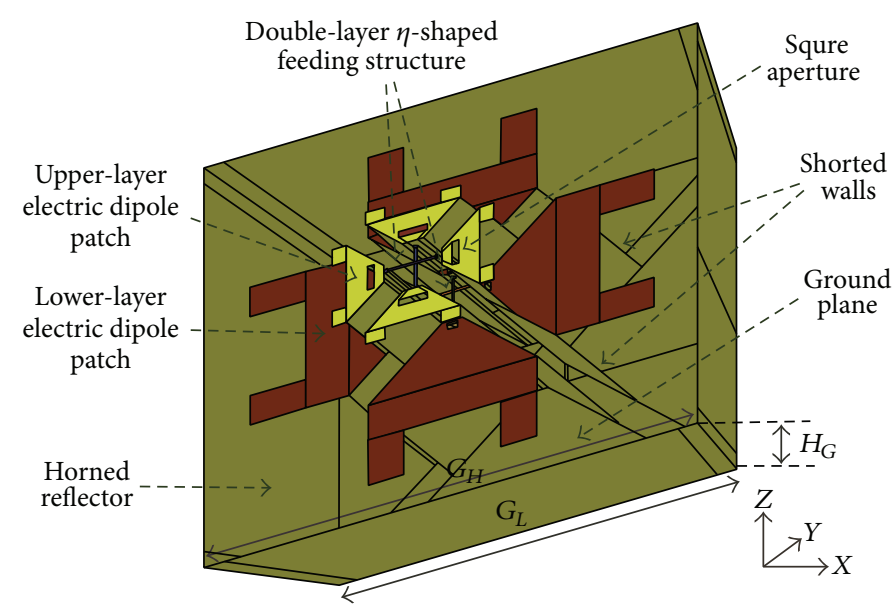

(a) $3 \mathrm{D}$ view

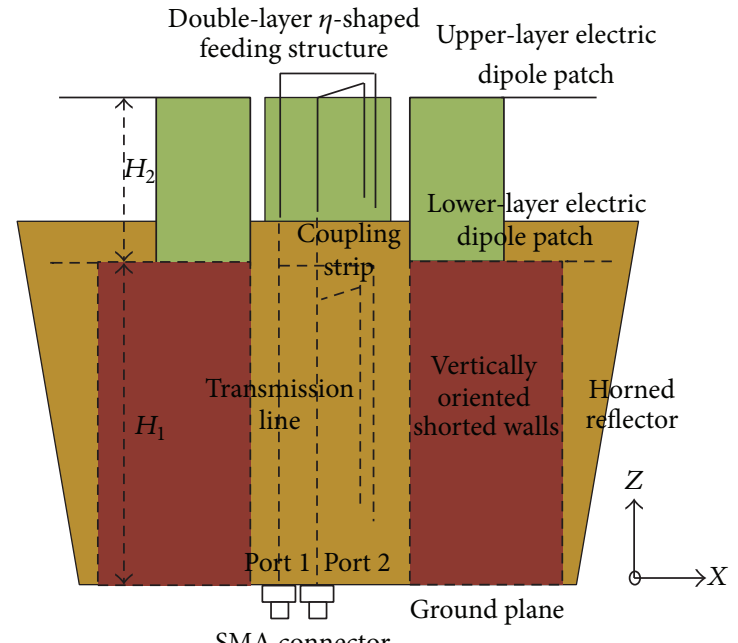

(c) Side view

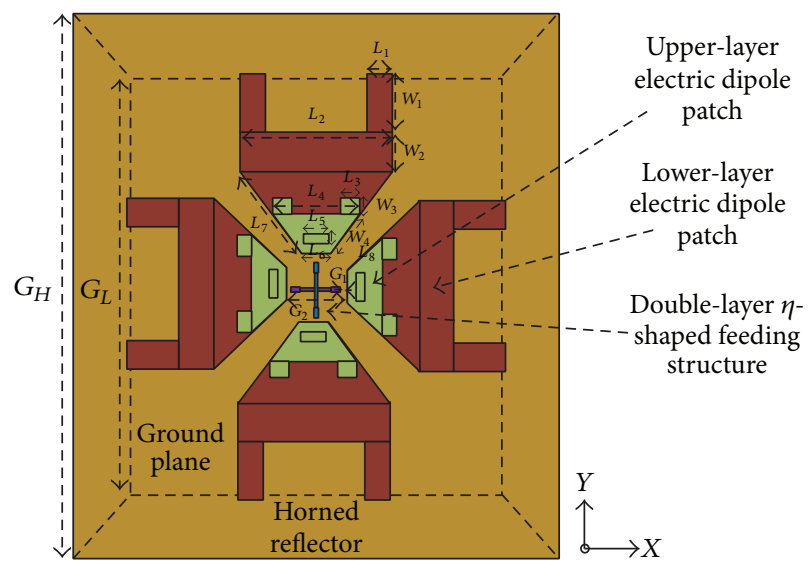

(b) Top view

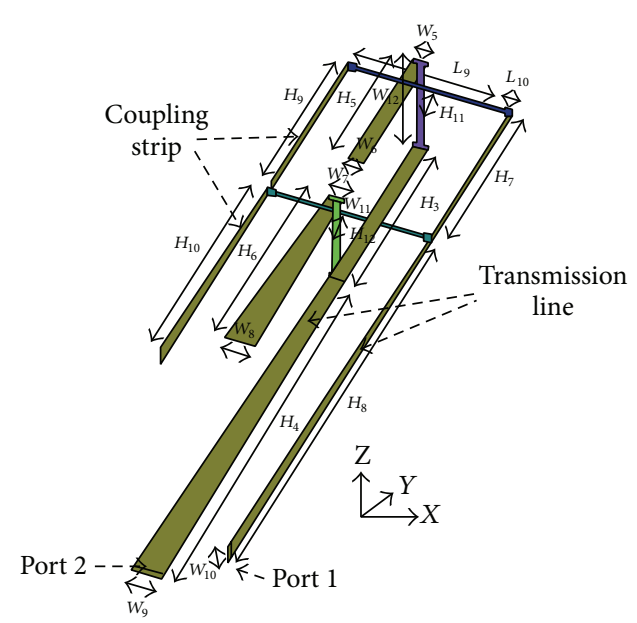

(d) Feeding structure

FIGURE 1: Geometry of the proposed antenna.

design, the differential reflection coefficients of differential ports 1 and $2\left(S_{d d 11}\right.$ and $\left.S_{d d 22}\right)$ can be regarded as

$$
S_{d d 11} \approx S_{d d 22} \text {. }
$$

The coupling coefficients of differential signal from differential ports 1 to $2\left(S_{d d 12}\right)$ and ports 2 to $1\left(S_{d d 21}\right)$ can be expressed as

$$
S_{d d 12}=S_{d d 21} .
$$

They can also be defined as antenna port isolation parameters. The impedance bandwidth of the proposed differentiallydriven dual-polarized antenna is defined as a range of frequencies over which the differential reflection coefficients for both $S_{d d 11}$ and $S_{d d 22}$ are less than $-10 \mathrm{~dB}\left(S_{d d 11} \leqslant-10 \mathrm{~dB}\right.$, $\left.S_{d d 22} \leqslant-10 \mathrm{~dB}\right)$.
On the other hand, based on [10], the far-field electric fields in the $E$ - and $H$-planes of a ME dipole antenna are the same and are expressed as

$$
\begin{aligned}
\vec{E}=j \frac{E_{y} d_{x} d_{y}}{2 \lambda r}[ & e_{\theta} \sin \varphi(1+\cos \theta) \\
& \left.+e_{\varphi} \cos \varphi(1+\cos \theta)\right] e^{-j k r}
\end{aligned}
$$

and the radiation pattern can be expressed as

$$
F(\theta)=\frac{(1+\cos \theta)}{2} .
$$

The back radiation can be cancelled as $\theta=180^{\circ}$ and $F(\theta)=$ 0 , while the front radiation can be enhanced as $\theta=0^{\circ}$ and $F(\theta)=1$. Besides, due to the complementary characteristics [15], the relationship between electromagnetic and magnetic fields can be described as

$$
\vec{E}=-j \vec{H} .
$$


TABLE 1: Dimensions for the proposed antenna.

\begin{tabular}{|c|c|}
\hline Parameters & Values/mm \\
\hline $\bar{L}$ & 15 \\
\hline$L_{2}$ & 70 \\
\hline$L_{3}$ & 8 \\
\hline$L_{4}$ & 39.6 \\
\hline$L_{5}$ & 8.5 \\
\hline$L_{6}$ & 12 \\
\hline$L_{7}$ & 44 \\
\hline$L_{8}$ & 22 \\
\hline$L_{9}$ & 20 \\
\hline$L_{10}$ & 1 \\
\hline$W_{1}$ & 23 \\
\hline$W_{2}$ & 18 \\
\hline$W_{3}$ & 6 \\
\hline$W_{4}$ & 2.8 \\
\hline$W_{5}$ & 2 \\
\hline$W_{6}$ & 2 \\
\hline$W_{7}$ & 2 \\
\hline$W_{8}$ & 4 \\
\hline$W_{9}$ & 4 \\
\hline$W_{10}$ & 4 \\
\hline$W_{11}$ & 22 \\
\hline$W_{12}$ & 22 \\
\hline$H_{1}$ & 59.5 \\
\hline $\mathrm{H}_{2}$ & 27.5 \\
\hline $\mathrm{H}_{3}$ & 25 \\
\hline $\mathrm{H}_{4}$ & 63 \\
\hline $\mathrm{H}_{5}$ & 23 \\
\hline$H_{6}$ & 33 \\
\hline $\mathrm{H}_{7}$ & 26 \\
\hline$H_{8}$ & 59 \\
\hline$H_{9}$ & 23 \\
\hline$H_{10}$ & 30 \\
\hline$H_{11}$ & 1 \\
\hline$H_{12}$ & 1.5 \\
\hline$H_{G}$ & 64 \\
\hline$G_{H}$ & 206 \\
\hline$G_{L}$ & 166 \\
\hline$G_{1}$ & 1 \\
\hline$G_{2}$ & 24 \\
\hline
\end{tabular}

That is to say, good complementary radiation pattern can be achieved since electric dipole and magnetic dipole are equivalent to working in turn. In our design, the dual-layer U-shaped electric dipole and portion of the magnetic dipole are orthogonal. They collaborate with each other to provide complementary radiation patterns.

3.2. Parametric Study. To observe how the dimensions of the antenna affect the performances, a parametric study is carried out by electromagnetic simulation software, IE3D [16]. Throughout the course of the study, the metallic layers are

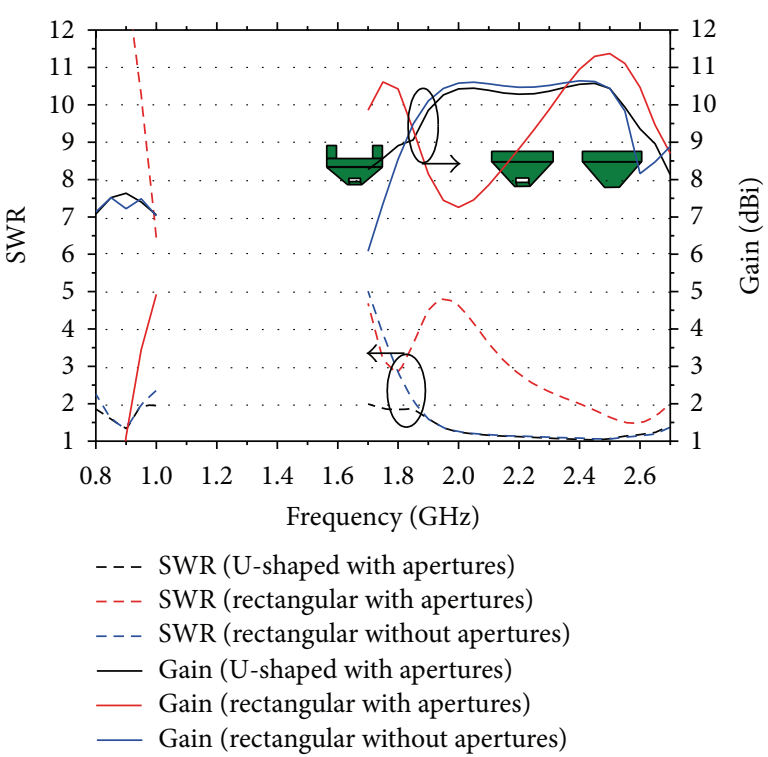

Figure 2: Effects of the electric dipoles in different shapes.

set to $0.3 \mathrm{~mm}$ thickness for practical applications. When one parameter is studied, the others are constant. To obtain stable gain, excellent impedance matching, and high port isolation, some important parameters of the dual-layer U-shaped electric dipoles, biorthogonal dual-layer $\eta$-shaped tapered line feeding structure and horned reflector are selected for study.

3.2.1. Effect of Dual-Layer U-Shaped Electric Dipoles. To reveal the impact of the U-shaped electric dipoles with apertures, the electric dipoles in different shapes are investigated while keeping the width of $W_{2}=18 \mathrm{~mm}$ constant. The length of $W_{1}$ at $0 \mathrm{~mm}$ with apertures (rectangular electric dipoles with apertures), $23 \mathrm{~mm}$ with apertures (U-shaped electric dipoles with apertures), and $23 \mathrm{~mm}$ without apertures (rectangular electric dipoles without apertures) is compared in the aspects of SWR and peak gain.

As is shown in Figure 2, at the lower frequency band, the SWR of the rectangular electric dipoles rises sharply and the gain drops correspondingly, while the other has no obvious fluctuation. Besides, at the two ends of the upper frequency band, the gain of the proposed antenna is more stable than the other with changes in the range of $2 \mathrm{dBi}$. In the other part of the upper frequency band, the SWRs and the gains of the proposed antenna keep stable. This is because the U-shaped electric dipoles with apertures are better in impedance matching and radiation patterns. Hence, the proposed electric dipoles can broaden the impedance bandwidth significantly and keep gain stable.

In addition, to depict the working mechanism of the double-layer U-shaped electric dipoles with apertures, the simulations of surface current distributions at $0.9 \mathrm{GHz}$, 1.8 GHz, and $2.6 \mathrm{GHz}$ are carried out, as is shown in Figure 3.

It is clearly seen that the current distribution at $0.9 \mathrm{GHz}$ demonstrates much stronger currents around the lower-layer electric dipoles than the upper-layer ones. However, the current distributions on the upper-layer electric dipoles are 

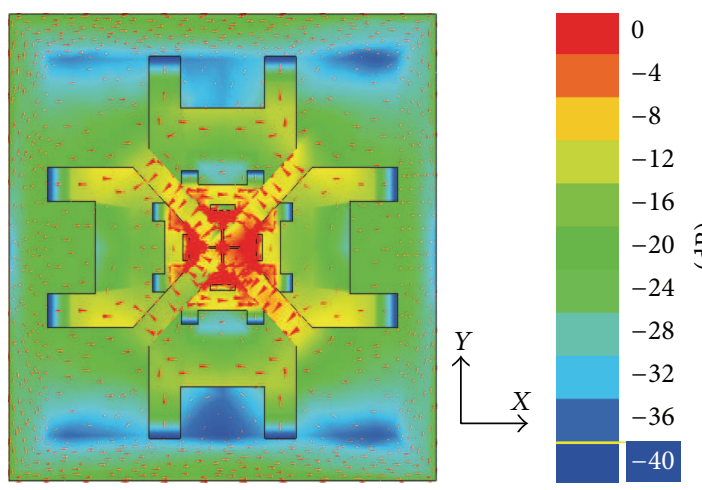

(a) $0.9 \mathrm{GHz}$

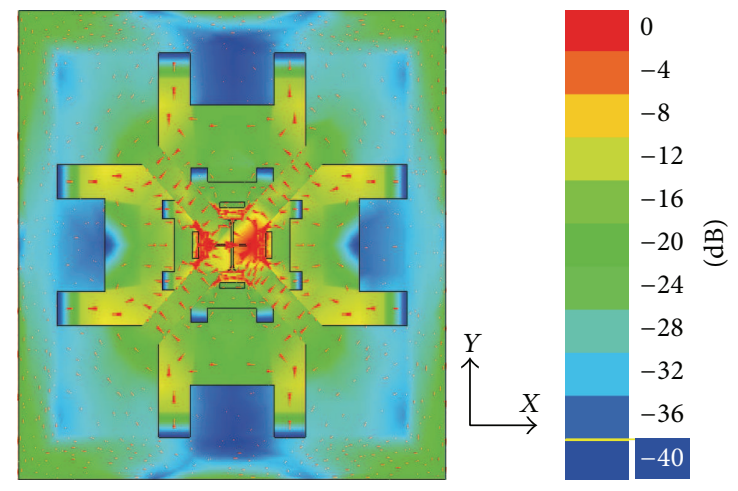

(b) $1.8 \mathrm{GHz}$

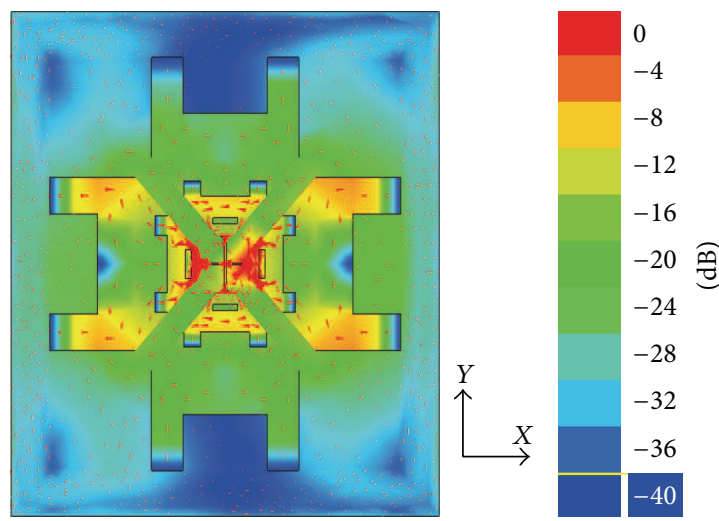

(c) $2.6 \mathrm{GHz}$

FIGURE 3: Current distributions on the electric dipoles.

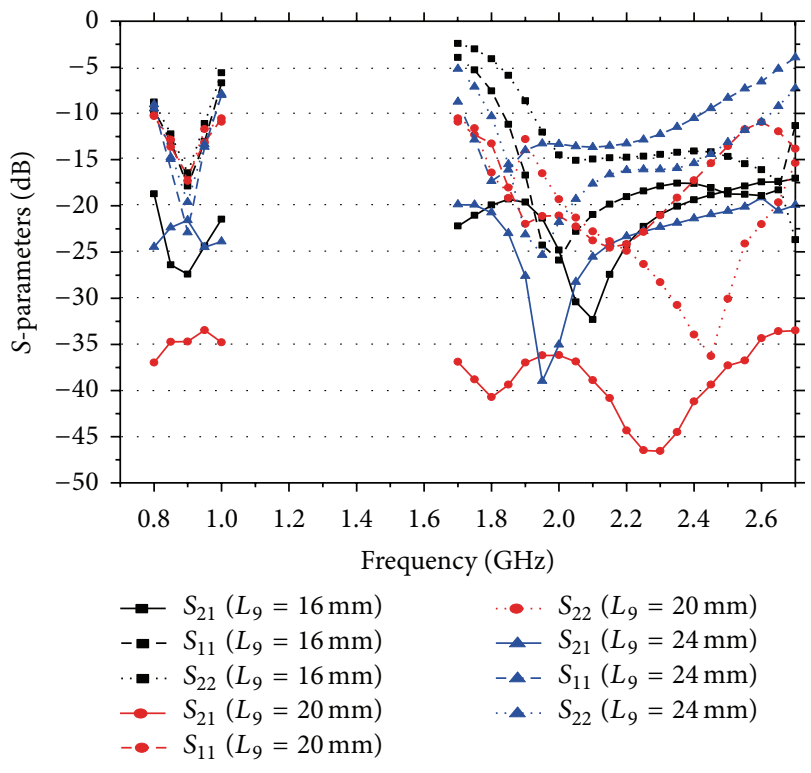

FIGURE 4: Effects of the $L_{9}$.

significantly enhanced as the frequency increases. In other words, the lower-layer electric dipoles mainly serve the lower frequency band, while the upper-layer electric dipoles chiefly work for the upper frequency band. Moreover, the current intensity around the apertures and the U-shaped notches etched in the electric dipoles is greater than the ones in other places and hence are equivalent to radiation elements. That is to say, the apertures and the U-shaped notches can increase the impedance bandwidth without increasing the patch area.

\subsubsection{Effect of Biorthogonal Dual-Layer $\eta$-Shaped Tapered} Line Feeding Structure. As mentioned above, in reality, the dual-layer $\eta$-shaped feeding strip can be divided into two parts: the transmission line and the coupling strip. In our design, the coupling strip is a critical part to impedance bandwidth and port isolation of the antenna.

In order to reveal the impact of the horizontal portion of the strip, we firstly study the length of $L_{9}$ keeping its width constant for good performance. It can be found that the $S$ parameters are very sensitive to the length. As is shown in Figure 4, for the lower frequency band, a longer $L_{9}$ produces a wider bandwidth. However, both shorter and longer $L_{9}$ bring larger fluctuations in port isolation. For the upper frequency band, the change in port isolation is similar to the lower frequency band, while there is no obvious change in impedance bandwidth. On the contrary, the port isolation is more stable and below $-32 \mathrm{~dB}$ when $L_{9}$ is equal to $20 \mathrm{~mm}$ across the frequency range. Therefore, the length $L_{9}=20 \mathrm{~mm}$ is selected for the wide bandwidth and stable isolation.

The distance $H_{11}$ between the two orthogonal horizontal portions of coupling strip is also investigated on impedance 


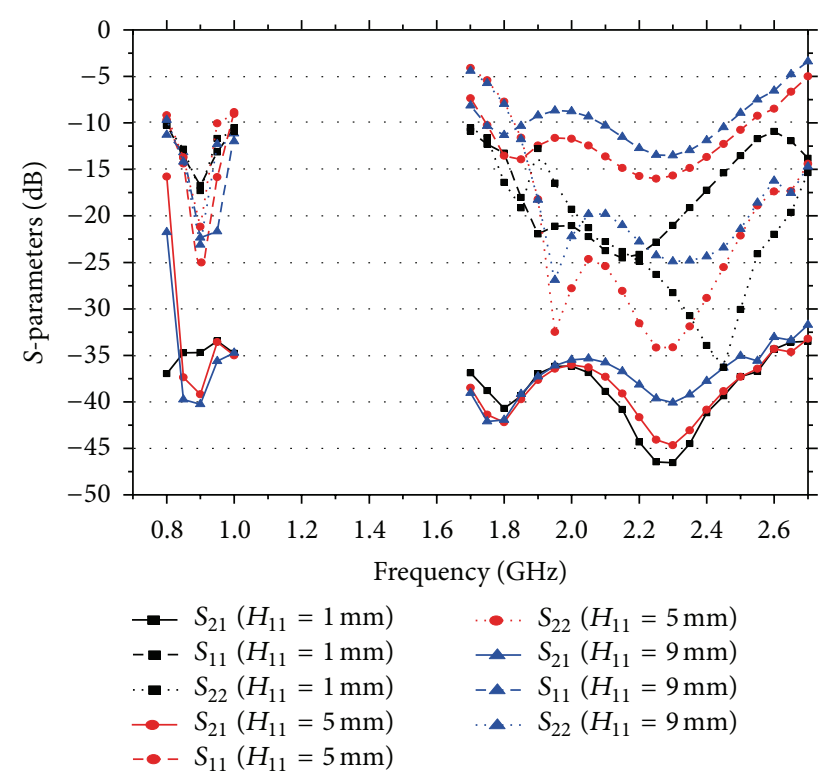

Figure 5: Effects of the $H_{11}$.

bandwidth and port isolation aspects. As is shown in Figure 5, at the lower frequency band, a shorter $H_{11}$ brings wider impedance bandwidth and more stable port isolation. At the upper frequency band, a shorter $H_{11}$ brings wider impedance bandwidth, while there is no marked change in port isolation. Hence, $H_{11}=1 \mathrm{~mm}$ is chosen for wide bandwidth and stable port isolation. In brief, the horizontal portion of coupling strip is significant for impedance bandwidth and port isolation.

3.2.3. Effect of Horned Reflector. Figure 6 shows the effects on simulated peak gains and SWRs under the conditions of adopting a horned reflector, a box-shaped reflector, or a planar plane reflector. Among them, the fence heights $\left(H_{G}\right)$ of the box-shaped and horned reflectors are the same. It can be easily observed that, with a horned reflector, the gain is more stable and the bandwidth is much wider than the other. In addition, with a planar reflector, the gain is the lowest.

As is shown in Figure 7, in comparison with radiation patterns, the proposed antenna with a horned reflector or with a box reflector has lower cross-polarization than the one with a planar reflector at lower frequency band. Besides, the front-to-back ratio of the proposed antenna with horned reflector or with a box reflector is higher than the others. This is because adopting the horned reflector or box reflector is more effective in keeping the radiation main beam unidirectional at lower frequency band. To sum up, it is an effective way to improve broadside gain and unidirectionality with the proposed horned reflector.

\section{Experimental Results}

To verify the proposed design, an antenna prototype according to the dimensions summarized in Table 1 was constructed, as is shown in Figure 8. Measured results of port

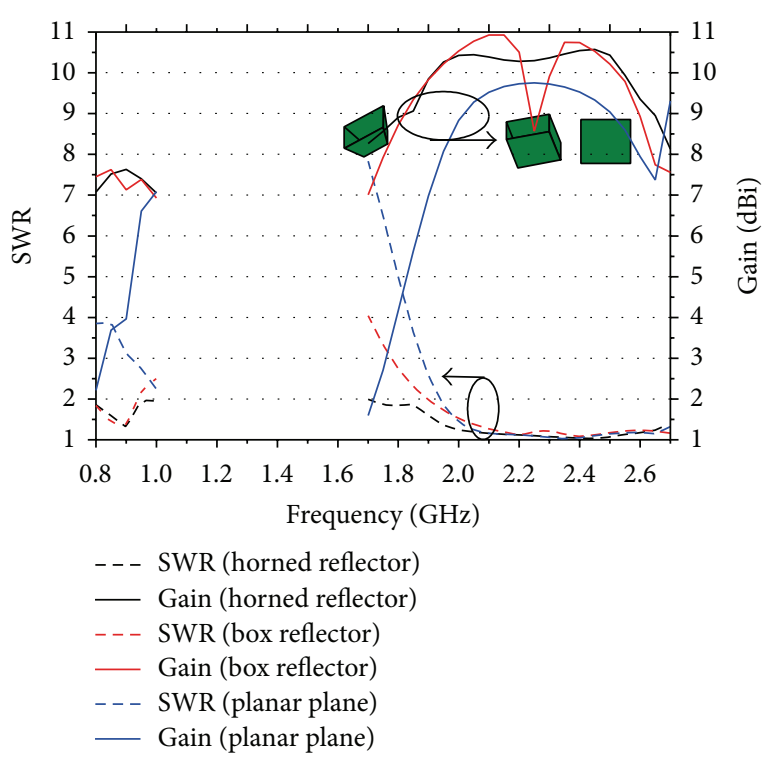

FIGURE 6: Effects of the reflectors.

isolation, SWR, antenna gain, and radiation patterns were obtained by Agilent E5071C network analyzer and SATIMO antenna measurement system.

\subsection{Isolation, SWR, and Gain}

4.1.1. Port Isolation. The simulated isolation and measured isolation between the input ports of lower and upper frequency bands are shown in Figure 9. It shows general agreement between them. It is easily observed that the measured input port isolation of better than $30 \mathrm{~dB}$ can be attained across the two frequency bands. In reality, port isolation of dual-band antenna greater than $28 \mathrm{~dB}$ is required to prevent the performance of a frequency band from being interfered by the other one. Thus, the port isolation of the proposed antenna can meet the requirements of multiple frequency communication system.

4.1.2. SWR and Gain. Figures 10 and 11 show the SWRs and gains of port 1 and port 2, respectively. It is easily observed that there is a slight difference between port 1 and port 2 in the operating frequency range. For port 1 , the measured impedance bandwidth ranges from 0.78 to $1.02 \mathrm{GHz}$ at the lower frequency band, while the measured impedance bandwidth ranges from 1.69 to $2.72 \mathrm{GHz}$ (SWR $\leq 2$ ) at the upper frequency band. For port 2, the measured impedance bandwidth ranges from 0.75 to $1.01 \mathrm{GHz}$ at the lower frequency band, while the measured impedance bandwidth ranges from 1.67 to $2.69 \mathrm{GHz}(\mathrm{SWR} \leq 2)$ at the upper frequency band. That is to say, the effective impedance bandwidth of the dual-polarized antenna is $25.7 \%$ ranging from 0.78 to $1.01 \mathrm{GHz}$ for the lower band and $45.7 \%$ ranging from 1.69 to $2.69 \mathrm{GHz}$ for the upper band. Both of them cover the frequency bands of $2 \mathrm{G} / 3 \mathrm{G} / \mathrm{LTE}$ systems. In addition, for port 1 , the measured gain varies between $7.2 \mathrm{dBi}$ and $7.9 \mathrm{dBi}$ in the lower band, while the measured antenna gain varies 


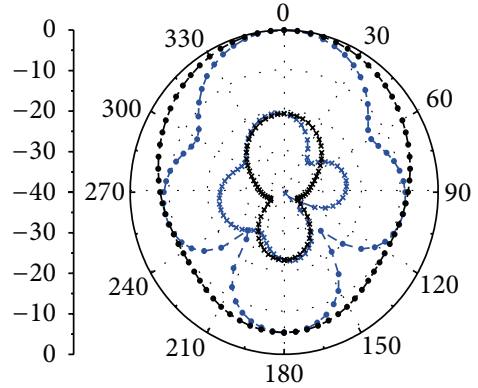

-- Co-pol (E-plane: XOZ-plane)

- - Co-pol (H-plane: XOY-plane)

-* - Cross-pol (E-plane: XOZ-plane)

-*-Cross-pol ( $H$-plane: XOY-plane)

(a) With a planar reflector

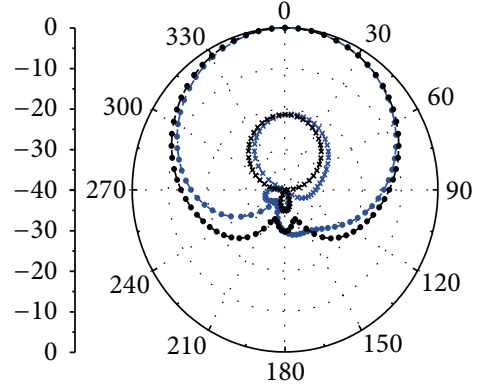

-- Co-pol (E-plane:XOZ-plane)

- - Co-pol (H-plane:XOY-plane)

-* - Cross-pol (E-plane: XOZ-plane)

-* - Cross-pol (H-plane:XOY-plane)

(b) With a box reflector

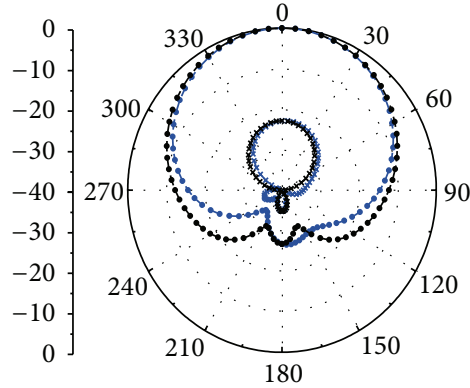

-- Co-pol (E-plane: XOZ-plane)

- - Co-pol (H-plane:XOY-plane)

-* - Cross-pol (E-plane: XOZ-plane)

-* - Cross-pol (H-plane: XOY-plane)

(c) With a horn reflector

FIGURE 7: Effects of the reflectors (radiation patterns at $0.9 \mathrm{GHz}$ ).

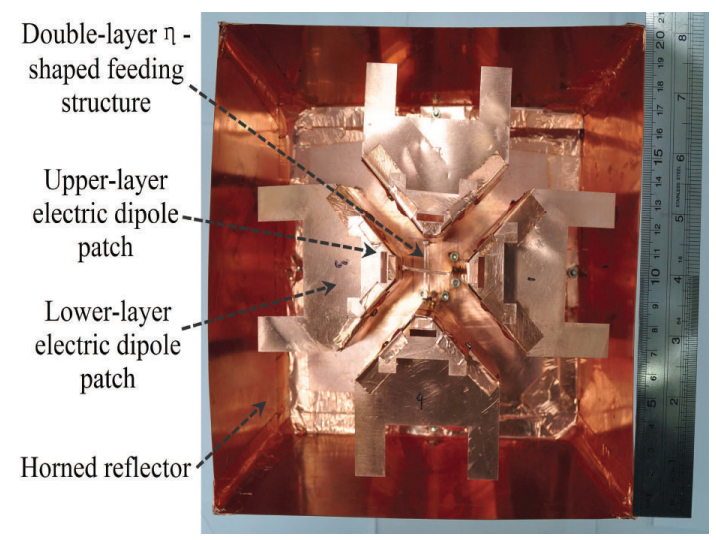

(a) Top view

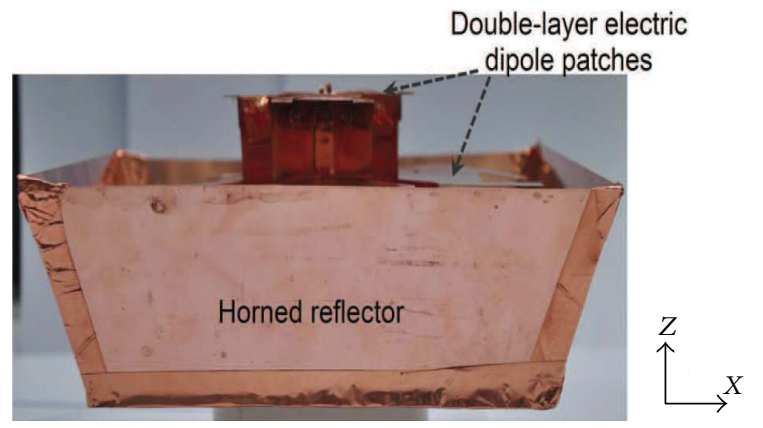

(c) Side view

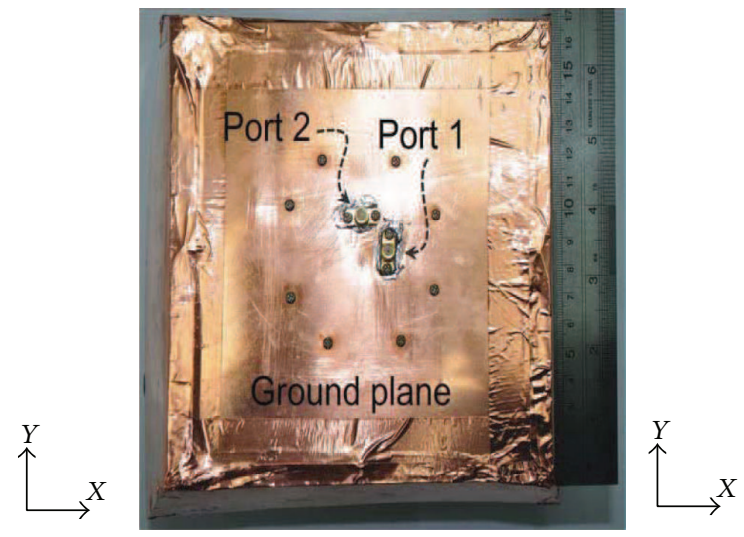

(b) Bottom view

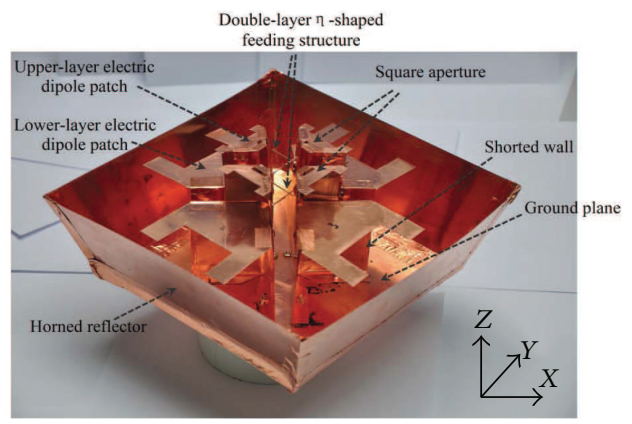

(d) $3 \mathrm{D}$ view

FIgURE 8: Photos of the proposed antenna.

between $8.4 \mathrm{dBi}$ and $10.6 \mathrm{dBi}$ in the upper band. For port 2, the measured gain varies between $7.1 \mathrm{dBi}$ and $8.5 \mathrm{dBi}$ in the lower band, while the measured antenna gain varies between $8.4 \mathrm{dBi}$ and $10.5 \mathrm{dBi}$ in the upper band. In other words, for the proposed antenna, the gain range is $7.8 \pm 0.7 \mathrm{dBi}$ at the lower frequency band, while the gain range is $9.5 \pm 1.1 \mathrm{dBi}$ at the upper frequency band. Hence, the gains are relatively stable and high enough for 2G/3G/LTE communication systems.
4.2. Radiation Patterns. The simulated and measured radiation patterns of port 1 and port 2 at frequencies of $0.9 \mathrm{GHz}$, $1.8 \mathrm{GHz}$, and $2.6 \mathrm{GHz}$ are shown in Figure 12, respectively. Detailed radiation characteristics of the proposed antenna are summarized in Table 2. Good agreement is achieved. The antenna displays excellent unidirectional radiation patterns. Over the operating frequency range, nearly symmetric and equal radiation patterns in the $E$ - and $H$-planes are achieved. In addition, the measured cross-polarization levels in $E$ - and 
TABLE 2: Experiment result of the radiation characteristic of the proposed antenna.

\begin{tabular}{|c|c|c|c|c|c|c|c|c|}
\hline \multirow{2}{*}{ Frequency $(\mathrm{GHz})$} & \multicolumn{4}{|c|}{ Port 1} & \multicolumn{4}{|c|}{ Port 2} \\
\hline & $\begin{array}{l}E \text {-plane (3 dB } \\
\text { Beam-width) }\end{array}$ & $\begin{array}{c}H \text {-plane } \\
\text { (3 dB } \\
\text { Beam-width) }\end{array}$ & $\begin{array}{c}\text { Cross- } \\
\text { polarization } \\
(\mathrm{dB})\end{array}$ & $\begin{array}{c}\text { Back-lobe } \\
\text { radiation } \\
(\mathrm{dB})\end{array}$ & $\begin{array}{l}E \text {-plane (3 dB } \\
\text { Beam-width) }\end{array}$ & $\begin{array}{c}H \text {-plane } \\
\text { (3 dB } \\
\text { Beam-width) }\end{array}$ & $\begin{array}{c}\text { Cross- } \\
\text { polarization } \\
(\mathrm{dB})\end{array}$ & $\begin{array}{c}\text { Back-lobe } \\
\text { radiation } \\
(\mathrm{dB})\end{array}$ \\
\hline 0.9 & $74^{\circ}$ & $78^{\circ}$ & -24 & -18 & $72^{\circ}$ & $78^{\circ}$ & -24 & -24 \\
\hline 1.8 & $49^{\circ}$ & $68^{\circ}$ & -25 & -20 & $32^{\circ}$ & $50^{\circ}$ & -26 & -18 \\
\hline 2.6 & $38^{\circ}$ & $101^{\circ}$ & -25 & -18 & $44^{\circ}$ & $100^{\circ}$ & -26 & -18 \\
\hline
\end{tabular}

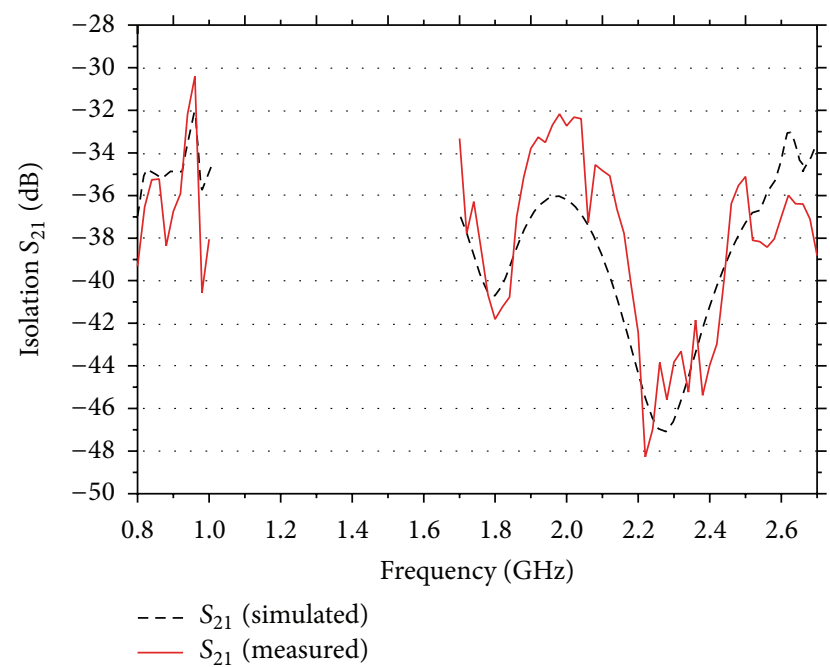

FIGURE 9: Simulated and measured S-parameters.

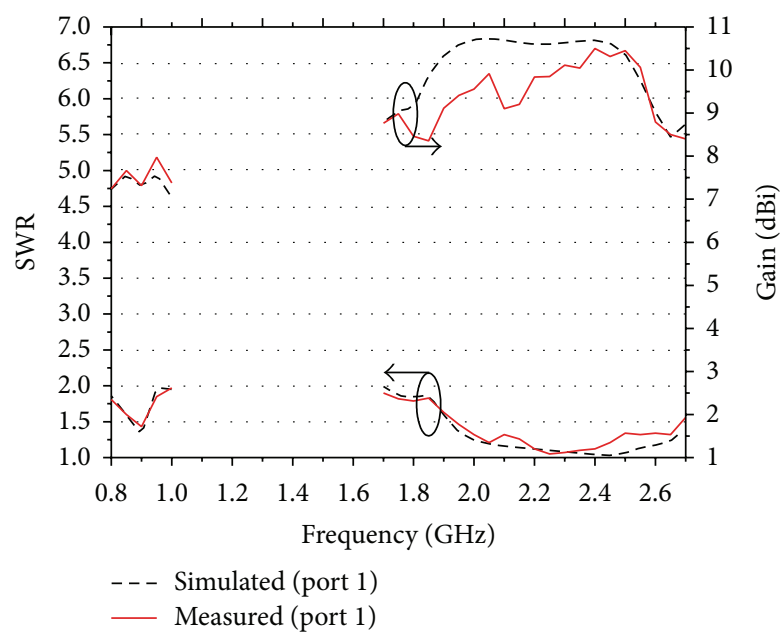

FIGURE 10: Simulated and measured SWRs and gains of port 1.

$H$-planes are generally below $-24 \mathrm{~dB}$, while the front-toback ratios are larger than $16 \mathrm{~dB}$ across the whole frequency bandwidth. Since the simulated cross-polarized radiation levels of port 1 and port 2 at $1.8 \mathrm{GHz}$ are lower than $-40 \mathrm{~dB}$, they cannot be shown in the graphs. Moreover, the radiation

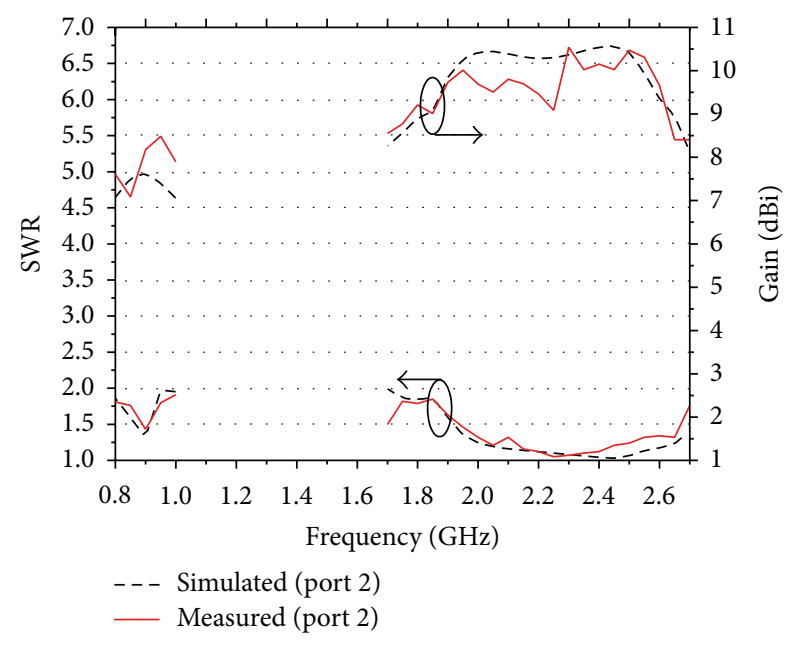

FIGURE 11: Simulated and measured SWRs and gains of port 2.

patterns of port 1 and port 2 are nearly the same and thus the proposed dual-polarization antenna is suitable for transmitting ideal differential signals.

\section{Conclusion}

A novel differentially driven dual-wideband double-layer complementary unidirectional antenna with a biorthogonal feeding structure for $2 \mathrm{G} / 3 \mathrm{G} / \mathrm{LTE}$ applications is proposed. The design has been verified through measurements on a prototype antenna. The results show good performance in terms of wide bandwidth and stable gain, which are $25.7 \%(0.78-1.01 \mathrm{GHz})$ and $7.8 \pm 0.7 \mathrm{dBi}$ for the lower band, $45.7 \%(1.69-2.69 \mathrm{GHz})$ and $9.5 \pm 1.1 \mathrm{dBi}$ for the upper band. Low cross-polarization, high front-to-back ratio, and nearly symmetrical $E$ - and $H$-plane patterns are achieved in both simulated and measured results. Moreover, input isolation exceeding $30 \mathrm{~dB}$ has been obtained between the two ports across the wide bandwidth. Last but not least, compared with the existing ME dipole antennas, the proposed antenna which is completely made of copper patches without dielectric loading can be easily fabricated at relatively low cost. All these features make the proposed antenna quite suitable for 2G/3G/LTE systems. 


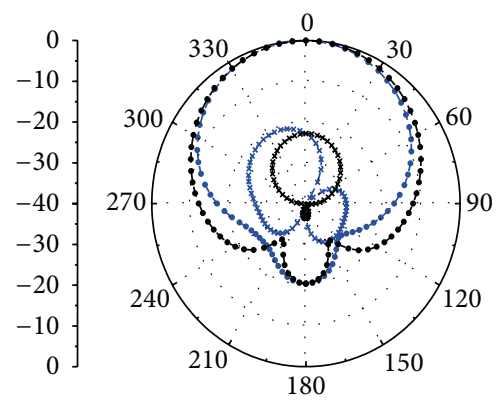

(a) Port 1 at $0.9 \mathrm{GHz}$ (simulated)

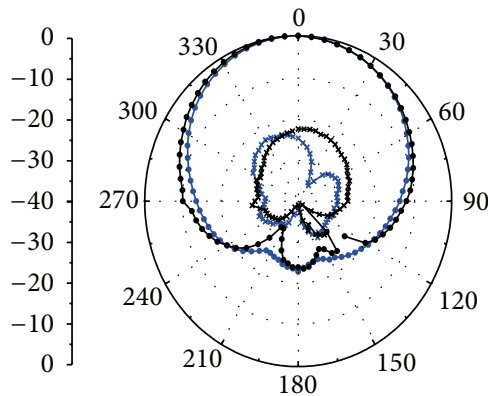

(d) Port 1 at $0.9 \mathrm{GHz}$ (measured)

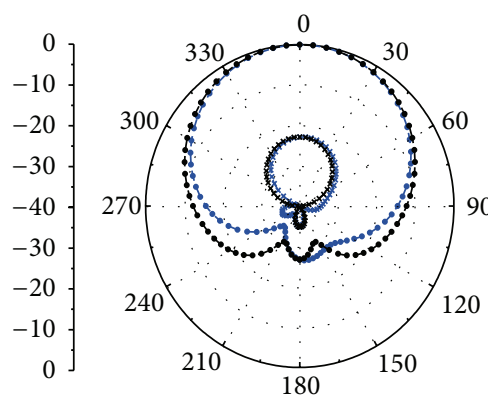

(g) Port 2 at $0.9 \mathrm{GHz}$ (simulated)
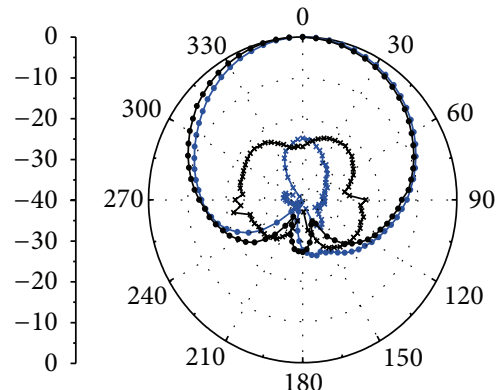

- Measured co-pol (H-plane: XOY-plane)

* Measured cross-pol (H-plane: XOY-plane)

$\rightarrow$ Measured co-pol (E-plane: XOZ-plane)

* Measured cross-pol (E-plane: XOZ-plane)

- - Simulated co-pol (H-plane: XOY-plane)

-*- Simulated cross-pol (H-plane: XOY-plane)

- - Simulated co-pol (E-plane: XOZ-plane)

-*-Simulated cross-pol (E-plane: XOZ-plane)

(j) Port 2 at $0.9 \mathrm{GHz}$ (measured)

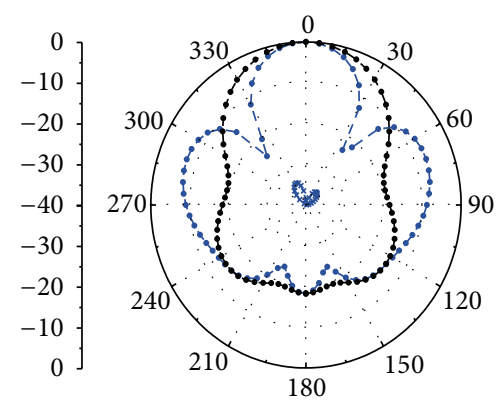

(b) Port 1 at $1.8 \mathrm{GHz}$ (simulated)

$$
\left.\begin{array}{r}
0 \\
-10 \\
-20 \\
-30 \\
-40 \\
-30 \\
-20 \\
-10 \\
0
\end{array}\right]
$$

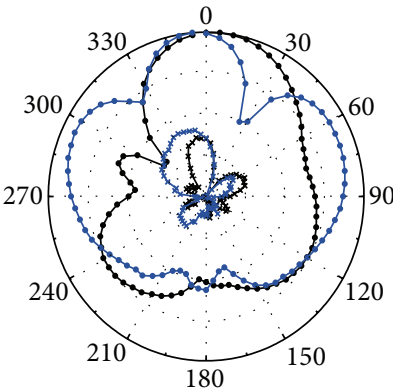

(e) Port 1 at $1.8 \mathrm{GHz}$ (measured)

$$
\left.\begin{array}{r}
0 \\
-10 \\
-20 \\
-30 \\
-40 \\
-30 \\
-20 \\
-10 \\
0
\end{array}\right]
$$

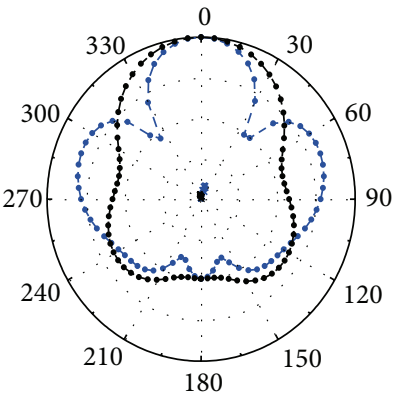

(h) Port 2 at $1.8 \mathrm{GHz}$ (simulated)
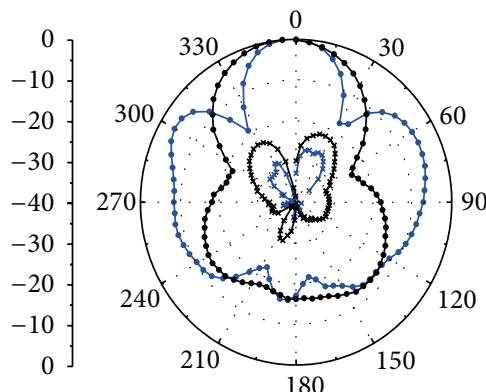

- Measured co-pol (H-plane: XOY-plane) * Measured cross-pol ( $H$-plane: $X O Y$-plane) - Measured co-pol (E-plane: XOZ-plane)

$*$ Measured cross-pol (E-plane: XOZ-plane)

- - Simulated co-pol ( $H$-plane: XOY-plane)

-*-Simulated cross-pol (H-plane: XOY-plane)

- Simulated co-pol (E-plane: XOZ-plane)

-*-Simulated cross-pol (E-plane: XOZ-plane)

(k) Port 2 at $1.8 \mathrm{GHz}$ (measured)

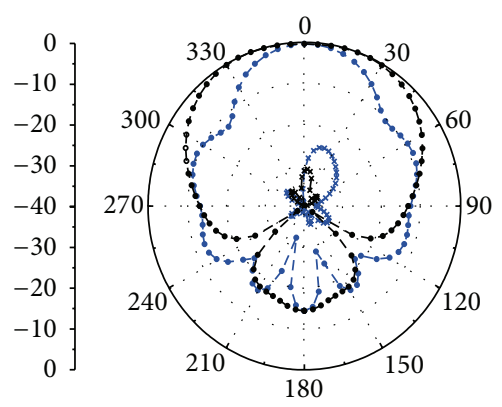

(c) Port 1 at $2.6 \mathrm{GHz}$ (simulated)

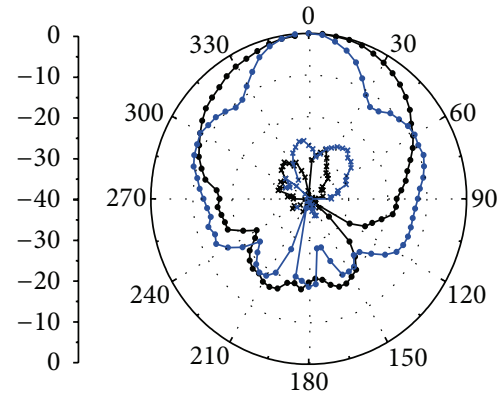

(f) Port 1 at $2.6 \mathrm{GHz}$ (measured)

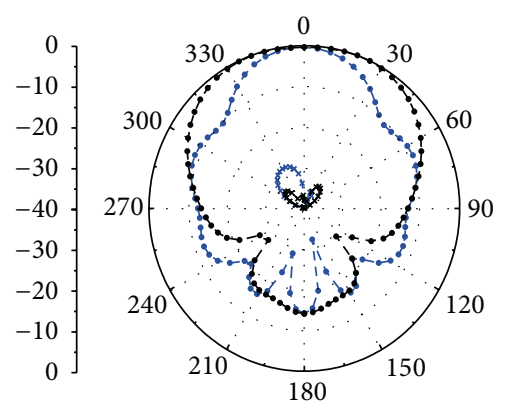

(i) Port 2 at $2.6 \mathrm{GHz}$ (simulated)

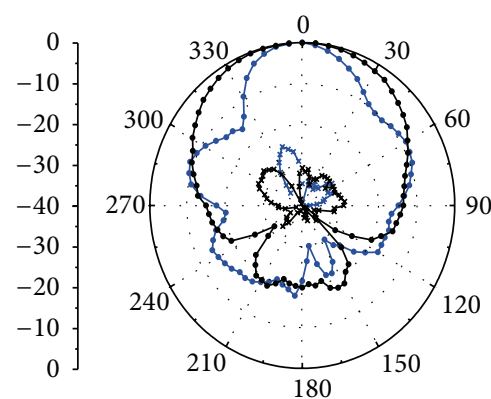

Measured co-pol (H-plane: XOY-plane) * Measured cross-pol ( $H$-plane: XOY-plane) - Measured co-pol (E-plane: XOZ-plane)

$*$ Measured cross-pol (E-plane: XOZ-plane)

- - Simulated co-pol ( $H$-plane: $X O Y$-plane)

-*- Simulated cross-pol ( $H$-plane: XOY-plane)

- Simulated co-pol (E-plane: XOZ-plane)

- - Simulated cross-pol (E-plane: XOZ-plane)

(l) Port 2 at $2.6 \mathrm{GHz}$ (measured)

FIGURE 12: Simulated and measured radiation patterns of port 1 and port 2 at $0.9 \mathrm{GHz}, 1.8 \mathrm{GHz}$, and 2.6 GHz. 


\section{Conflict of Interests}

The authors declare that there is no conflict of interests regarding the publication of this paper.

\section{Acknowledgment}

The research was supported by grants from the National Natural Science Foundation of China (No. 61139001), National Science and Technology Major Project (No. 2012ZX03003006), Fundamental Research Funds for the Central Universities (2011PTB-00-33) and Postgraduate Innovation Fund of R\&S-BUPT, 2013. The authors would like to thank Dr. Hang Wong of the State Key Laboratory of Millimeter Waves, City University of Hong Kong for many helpful discussions and the suggestion to revise the paper.

\section{References}

[1] O. M. Haraz, A.-R. Sebak, and T. A. Denidni, "Dual-polarised dielectric-loaded monopole antenna for wideband communication applications," IET Microwaves, Antennas and Propagation, vol. 6, no. 6, pp. 663-669, 2012.

[2] Y.-X. Guo, K.-M. Luk, and K.-F. Lee, "Broadband dual polarization patch element for cellular-phone base stations," IEEE Transactions on Antennas and Propagation, vol. 50, no. 2, pp. 251-253, 2002.

[3] B. Q. Wu and K.-M. Luk, "A broadband dual-polarized magneto-electric dipole antenna with simple feeds," IEEE Antennas and Wireless Propagation Letters, vol. 8, pp. 60-63, 2009.

[4] H. Wong, K.-L. Lau, and K.-M. Luk, "Design of dual-polarized L-probe patch antenna arrays with high isolation," IEEE Transactions on Antennas and Propagation, vol. 52, no. 1, pp. 45-52, 2004.

[5] S. Gao and A. Sambell, "Dual-polarized broad-band microstrip antennas fed by proximity coupling," IEEE Transactions on Antennas and Propagation, vol. 53, no. 1, pp. 526-530, 2005.

[6] M. Barba, "A high-isolation, wideband and dual-linear polarization patch antenna," IEEE Transactions on Antennas and Propagation, vol. 56, no. 5, pp. 1472-1476, 2008.

[7] Q. Xue, S. W. Liao, and J. H. Xu, "A differentially-driven dualpolarized magneto-electric dipole antenna," IEEE Transactions on Antennas and Propagation, vol. 61, no. 1, pp. 425-430, 2013.

[8] K. M. Luk and H. Wong, "A new wideband unidirectional antenna element," International Journal of Microwave and Optical Technology, vol. 1, no. 1, pp. 35-44, 2006.

[9] L. Ge and K. M. Luk, "A wideband magneto-electric dipole antenna," IEEE Transactions on Antennas and Propagation, vol. 60, no. 11, pp. 4987-4991, 2012.

[10] M. Li and K. M. Luk, "A low-profile wideband planar antenna," IEEE Transactions on Antennas and Propagation, vol. 61, no. 9, pp. 4411-4418, 2013.

[11] W. X. An, H. Wong, K. L. Lau, S. F. Li, and Q. Xue, "Design of broadband dual-band dipole for base station antenna," IEEE Transactions on Antennas and Propagation, vol. 60, no. 3, pp. 1592-1595, 2012.

[12] B. Feng, W. Hong, S. Li, W. An, and S. Yin, "A dual-wideband double-layer magnetoelectric dipole antenna with a modified horned reflector for $2 \mathrm{~g} / 3 \mathrm{~g} / \mathrm{lte}$ applications," International Journal of Antennas and Propagation, vol. 2013, Article ID 509589, 9 pages, 2013.

[13] J.-H. Lu and S.-W. You, "Novel dual-band design of planar dipole array for 4G LTE/WiMAX access points," International Journal of Antennas and Propagation, vol. 2011, Article ID 638034, 4 pages, 2011.

[14] W. X. An, K. L. Lau, S. F. Li, and Q. Xue, "Wideband E-shaped dipole antenna with staircase-shaped feeding strip," Electronics Letters, vol. 46, no. 24, pp. 1583-1584, 2010.

[15] A. Chlavin, "A new antenna feed having equal E- and Hplane patterns," Transactions of the IRE Professional Group on Antennas and Propagation, vol. 2, no. 3, pp. 113-119, 1954.

[16] Ie3d, Version 12.30, Zeland Software Inc., Fremont, Calif, USA, 2007. 

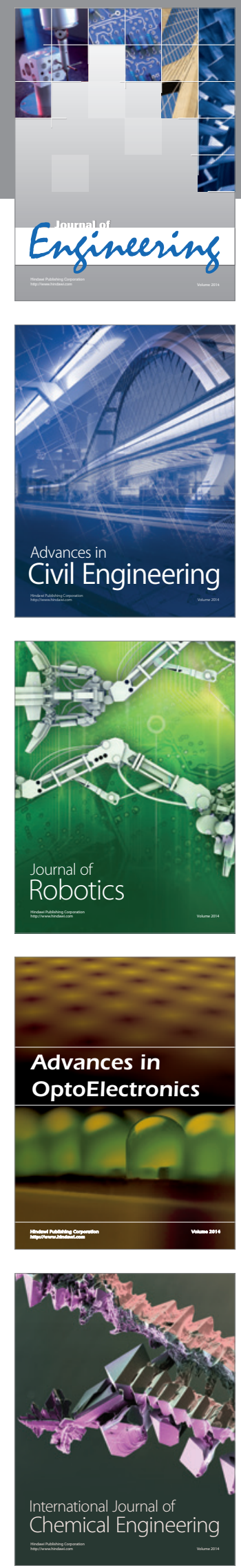

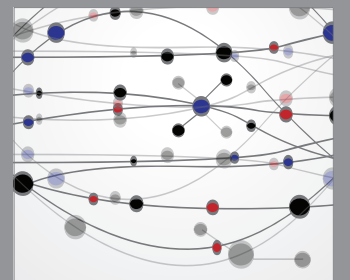

The Scientific World Journal
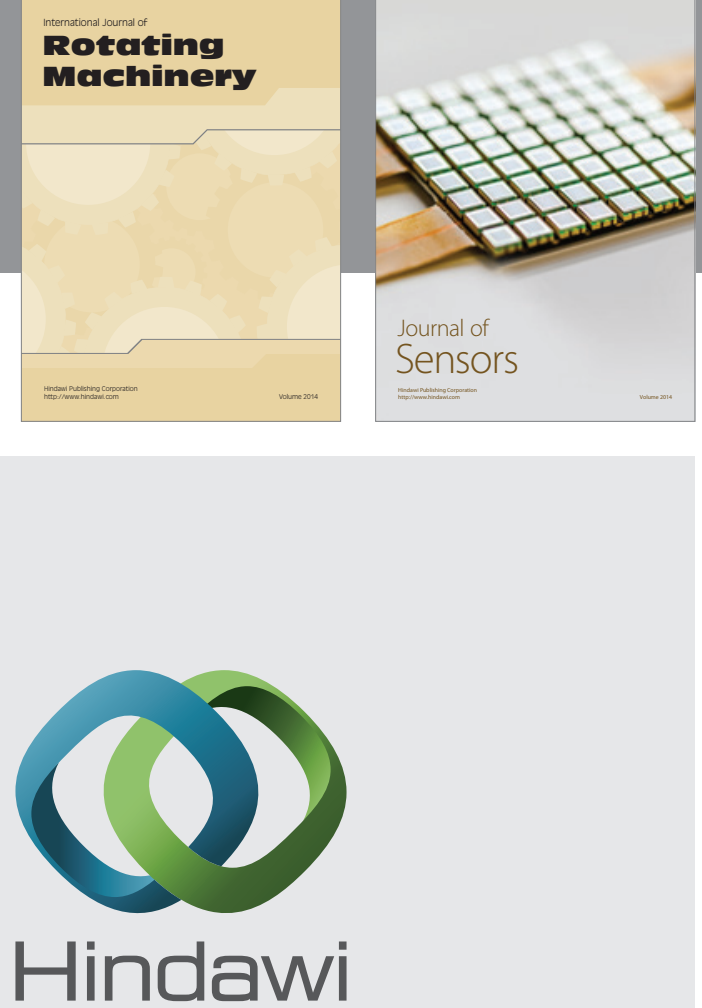

Submit your manuscripts at http://www.hindawi.com
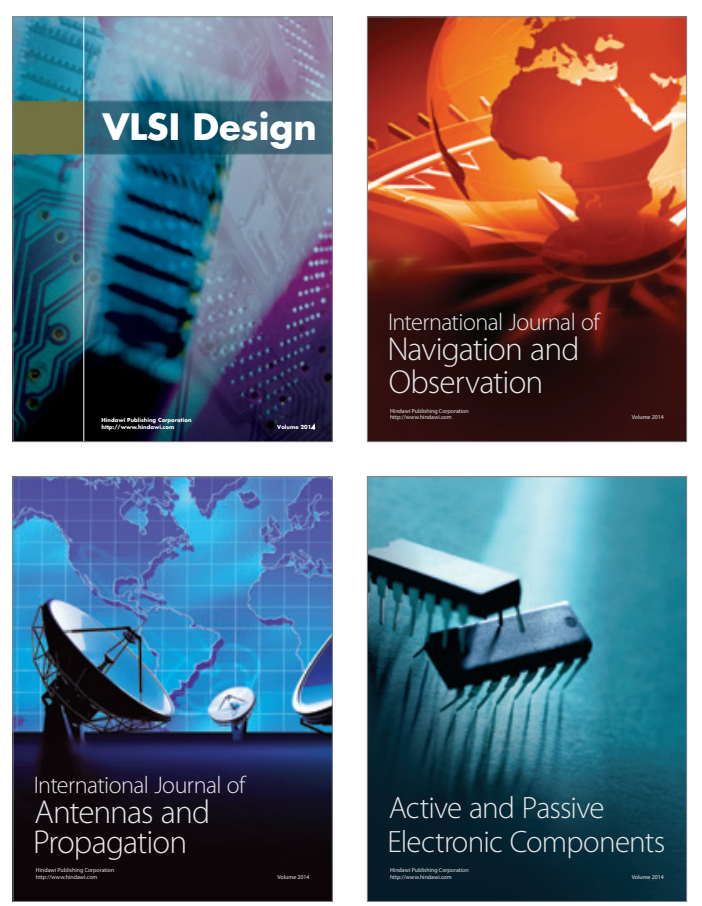
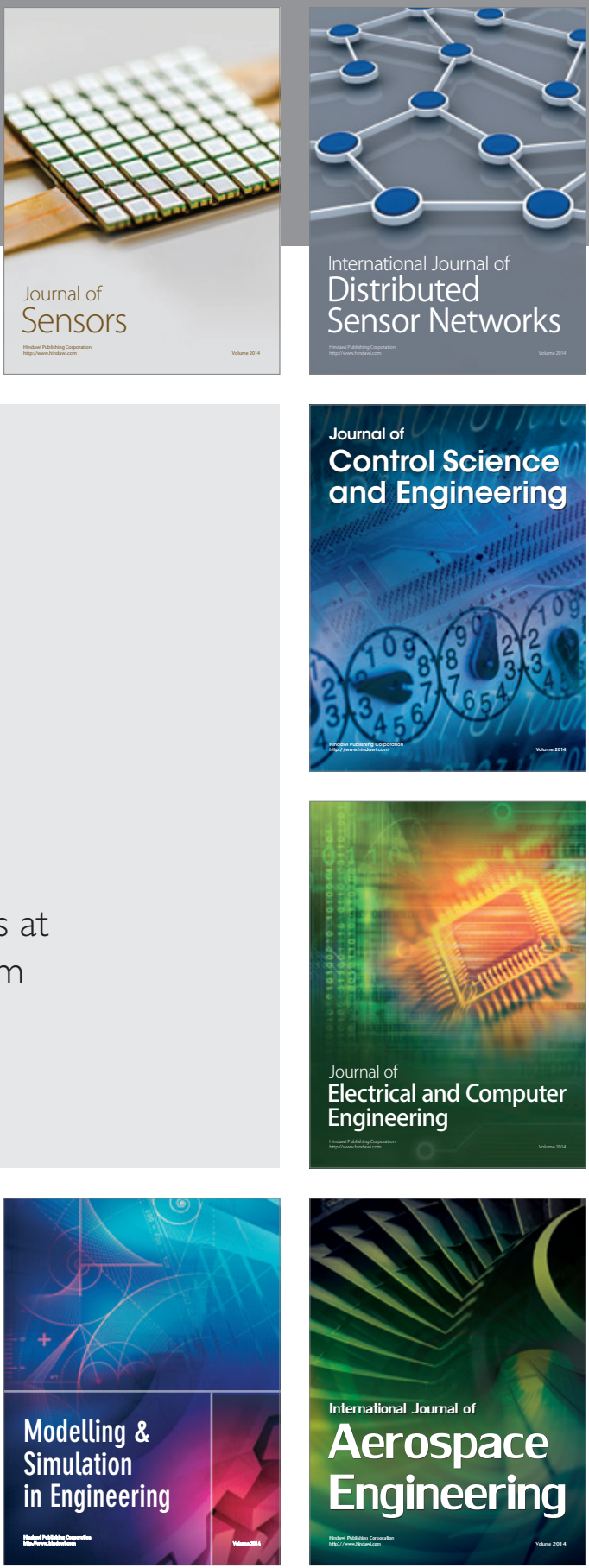

Journal of

Control Science

and Engineering
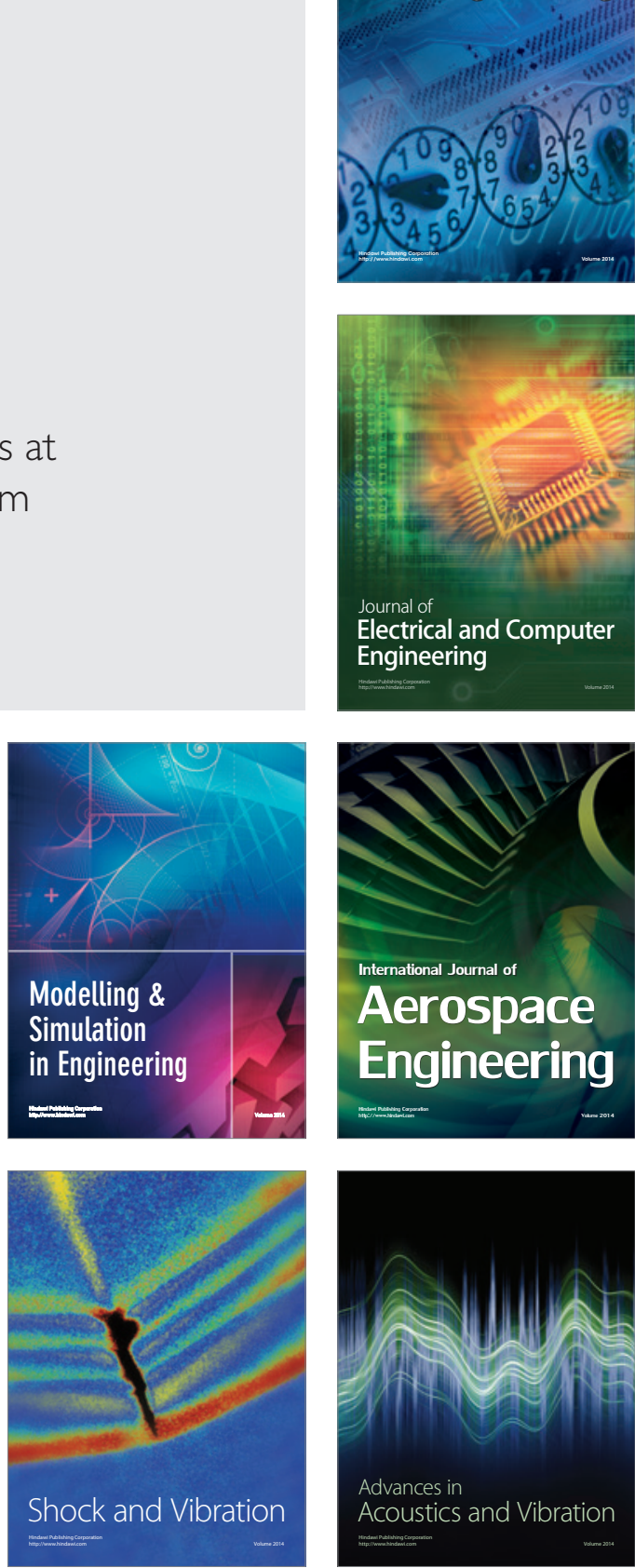